\title{
The efficacy of a lysine-based dendritic hydrogel does not differ from those of commercially available tissue sealants and adhesives: an ex vivo study
}

\author{
Juan C Villa-Camacho ${ }^{1}$, Cynthia Ghobril², Lorenzo Anez-Bustillos ${ }^{1}$, Mark W Grinstaff ${ }^{2}$, Edward K Rodríguez ${ }^{3+}$ \\ and Ara Nazarian ${ }^{1 *+}$
}

\begin{abstract}
Background: Hemostatic agents, tissue adhesives and sealants may contribute to a reduction in hemorrhage-associated morbidity and mortality. Towards this end, we have recently developed a lysine-based dendritic hydrogel (PEG-Lys $\left.\mathrm{NH}_{2}\right)$ that can potentially be used in the management of severe trauma and/or intraoperative bleeding. As a first step in demonstrating the potential utility of this approach, our objective was to ascertain the ability of the PEG-Lys $\mathrm{NH}_{2}$ to adhere to and seal injured tissues, as well as to maintain the seal under physiological conditions.
\end{abstract}

Methods: The efficacy of the PEG-Lys $\mathrm{NH}_{2}$ in sealing injured tissues was evaluated using an ex-vivo pressure testing system. A $2.5 \mathrm{~mm}$ incision was made on intact ex-vivo tissues and then sealed with the PEG-Lys $\mathrm{NH}_{2}$. Application of the PEG-Lys $\mathrm{NH}_{2}$ was followed by 1) step-wise pressure increase to a maximum of $250 \mathrm{mmHg}$ and 2) fluctuating pressures, between 100-180 mmHg with a rate of $3 \mathrm{~Hz}$, over a 24-hour period. The performance of the PEG-Lys $\mathrm{NH}_{2}$ was compared to those of commercially available sealants and adhesives.

Results: During gradual pressure increase, mean pressures at 30 seconds $\left(P_{30}\right)$ ranged between $206.36-220.17 \mathrm{mmHg}$ for the sealants, and they were greater than control and suture groups $(p<0.01$ and $p=0.013$, respectively). Additionally, all products held under fluctuating pressures: mean pressures ranged between $135.20-160.09 \mathrm{mmHg}$, and there were no differences observed between groups $(p=0.96)$.

Conclusions: The efficacy of the PEG-Lys $\mathrm{NH}_{2}$ was significantly superior to conventional injury repair methods (sutures) and did not differ from those of commercially available products when sealing small incisions.

Keywords: Hemostasis, Trauma, Hydrogel, Sealant, Adhesive, Dendron

\section{Background}

In the surgical setting, intraoperative bleeding that is unresponsive to conventional methods is associated with prolonged surgery times and significantly contributes to postoperative complications [1]. Topical hemostatic agents, sealants, and adhesives may be used during surgical procedures to achieve hemostasis when hemorrhage is not controlled by standard methods such as direct

\footnotetext{
* Correspondence: anazaria@bidmc.harvard.edu

${ }^{\dagger}$ Equal contributors

${ }^{1}$ Center for Advanced Orthopaedic Studies, Department of Orthopaedic Surgery, Beth Israel Deaconess Medical Center, Harvard Medical School, Boston, MA, USA

Full list of author information is available at the end of the article
}

pressure, vessel ligation, and suturing [2]. These products physically adhere to damaged tissues and seal injured blood vessels to prevent further blood loss [3]. Additionally, specific agents may accelerate the production of a fibrin thrombus by activating the coagulation cascade [4].

We have recently developed a lysine-based dendritic hydrogel $\left(\mathrm{PEG}-\mathrm{LysNH}_{2}\right)$ that can potentially be used in the management of severe trauma and/or intraoperative bleeding [5]. As a first step in demonstrating the potential utility of the PEG-LysNH ${ }_{2}$, it was necessary to ascertain its ability to adhere to and seal injured tissues, as well as to maintain the seal under physiological conditions. We 
hypothesized that the PEG-LysNH $\mathrm{H}_{2}$ would endure pressure testing in the absence of direct pressure by adhering to damaged tissue, and that its performance would be significantly better than that of conventional sutures and non-inferior to those of commercially available hemostatic agents, tissue adhesives and sealants.

\section{Methods}

\section{Synthesis of the PEG-Lys $\mathrm{NH}_{2}$}

The PEG-LysNH${ }_{2}$ was synthesized using a previously reported procedure [5]. Briefly, a solution of pegylated lysine dendron 1 in borate buffer at $\mathrm{pH} 9$ was reacted with a solution of poly(ethylene glycol disuccinimidyl valerate) of 3400 MW (2, SVA-PEG-SVA) in PBS buffer at pH 6.5 (Figure 1). The ratio of amine to SVA was 1:1, and the total concentration of polymer in solution was $30 \mathrm{wt} \%$. A hydrophilic gel formed spontaneously within seconds upon mixing the two aqueous solutions.

\section{Rheological characterization}

For each test material, cylindrical samples with a $9 \mathrm{~mm}$ diameter and $3 \mathrm{~mm}$ thickness were prepared in a precast Teflon mold and analyzed using $8 \mathrm{~mm}$ steel plate geometry. The mechanical strength and viscoelastic properties of the materials were investigated using dynamic rheological measurements and the frequency sweeps of all sealants and adhesives were measured at a frequency of 0.1 to $10 \mathrm{~Hz}$ with a controlled oscillatory stress of $50 \mathrm{~Pa}$ and at $20{ }^{\circ} \mathrm{C}$ (RA 1000, TA Instruments - New Castle, DE, USA) [5]. The shear storage $\left(G^{\prime}\right)$ and shear loss $\left(G^{\prime \prime}\right)$ describe the elastic or solid-like and viscous or liquid-like characteristics, respectively, of a material. G' values were reported as mean \pm SEM $(\mathrm{n}=3)$ for all sealants and adhesives, at $1 \mathrm{~Hz}$ of frequency and $50 \mathrm{~Pa}$ of oscillatory stress.

\section{Pressure testing}

The testing device consisted of a sensor assembly connected to a cylindrical reservoir (Figure 2). The sensor assembly contained a flow sensor (FLR-1007, Omega Engineering - Stamford, CT, USA) as well as a pressure sensor (PX-309, Omega Engineering - Stamford, CT, USA), which acquired data at a per-second rate and sent it to a data logger (DAQPRO-5300, Omega Engineering - Stamford, CT, USA). The sensor assembly was connected to the reservoir through polyvinyl chloride (PVC) pressure monitoring lines (MX561, Smiths Medical - Dublin, OH, USA) creating a closed system. The reservoir was lined with ex-vivo tissues (bovine aorta or murine skin) (Figure 2b), and $0.9 \%$ sodium chloride solution was fed into the system in either a continuous or pulsatile fashion - to simulate venous and arterial bleeding - using either a pressure infusor (Infusable, Vital Signs Inc. - Totowa, NJ, USA) or a peristaltic pump (SP04 L, Otto Huber GmbH Böttingen, Germany).

We compared the efficacy of the PEG-LysNH $\mathrm{H}_{2}$ to those of commercially available agents (Table 1 ). In order to comply with the original indications of the products, efficacy was tested on small wounds under dry conditions. Agents designed for vascular hemorrhage control were tested on bovine aortas, whereas topical agents were tested on murine skins. The PEG-LysNH$H_{2}$ was tested on both tissue types. All tissues used in the study were fresh frozen, preserved at $-20^{\circ} \mathrm{C}$ and thawed for 30 minutes before testing. All products were applied directly on the wound in multiple thin layers with syringe or "gun" dispensers. Mixture of the products took place on the dispenser (Dermabond, Omnex, PEG-LysNH ${ }_{2}$ ), the dispenser tip (BioGlue) or directly on the wound surface (Evicel). Only one application was attempted in all trials.

\section{Resistance to failure}

A $2.5 \mathrm{~mm}$ incision was made on the otherwise intact tissues and then sealed with the products $(n=3$ per group). Three control groups were included in the tests: 1) intact tissue, 2) incised tissues without sealing and 3) incised tissues repaired with sutures (two vertical mattress suture stitches with an approximate bite size of $3 \mathrm{~mm}$ for the large bite and $1.5 \mathrm{~mm}$ for the small bite) using 4-0 polypropylene. After 10 minutes, pressure within the system was increased, in a stepwise fashion, by $40 \mathrm{mmHg}$ every 5 seconds to a maximum of $250 \mathrm{mmHg}$, or until failure (noted by a sudden drop in pressure

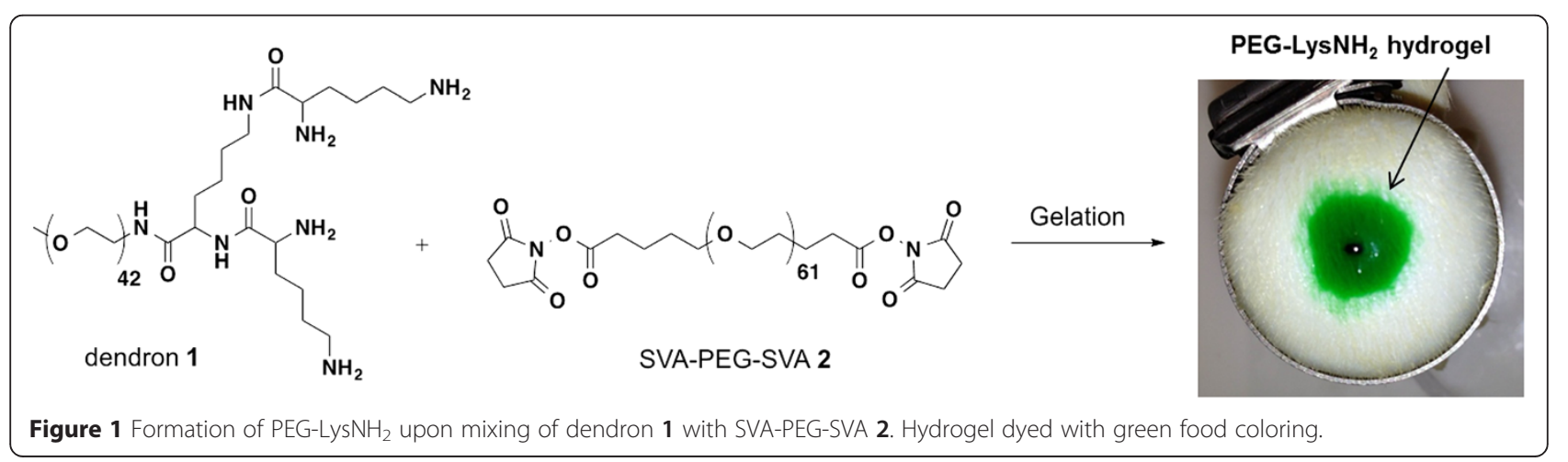




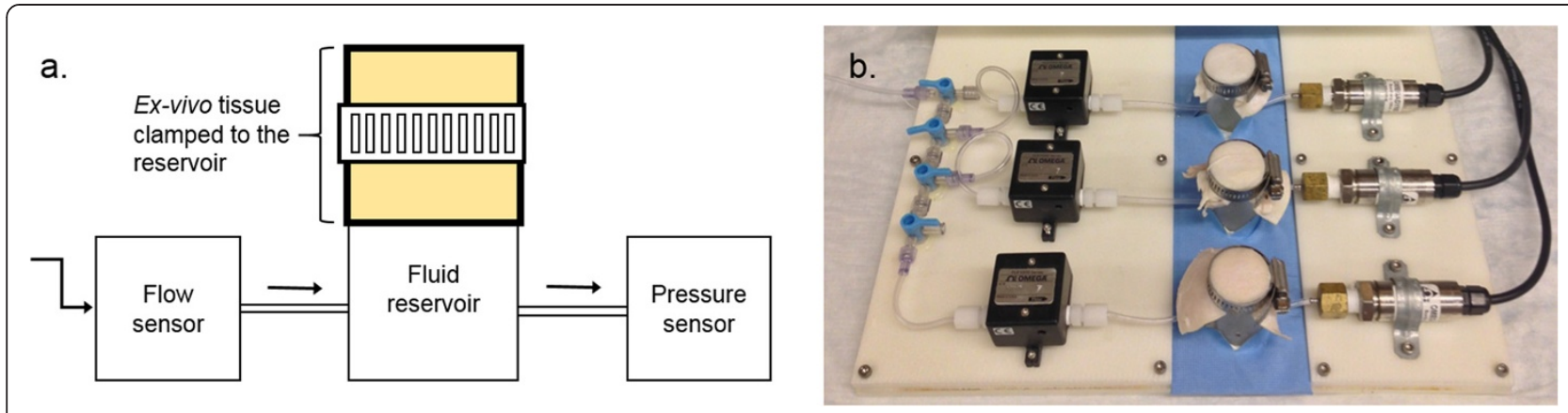

Figure $\mathbf{2}$ The failure testing device. a. Schematic representation of the testing device. Arrows indicate the direction of flow within the system; $\mathbf{b}$. Photograph of the EVAH testing device. Saline solution was fed into the system with an infusor or a peristaltic pump (not shown).

recordings, sudden rise in flow recordings, and visible leakage of saline through the wound). Mean pressure in the system at 30 seconds $\left(\mathrm{P}_{30}\right)$ was calculated and compared between groups using one-way analysis of variance (ANOVA). Bonferroni corrected, two-tailed $p$ values were used to establish statistically significant differences using $\alpha=0.05$ as the initial criterion. Relative standard error was calculated as an index of measurement reproducibility. Power calculations which indicated that 3 experiments would provide $88.1 \%$ power ( $\beta=0.881)$ to detect a difference of $25 \mathrm{mmHg}$ between treatment groups $(\delta=25 \mathrm{mmHg})$ using the standard deviation of $\mathrm{P}_{30}$ intact tissue $(\sigma=7.31 \mathrm{mmHg})$.

\section{Endurance}

We assessed the capacity of the products to hold and withstand fluctuating pressures analogous to human arterial pressures. A $2.5 \mathrm{~mm}$ incision was made on the otherwise intact tissue and then sealed with the products ( $n=3$ per group). A control group, of intact tissues only (without incisions) was included in this experimental phase. After 10 minutes, the system was subjected to fluctuating pressures (between 100 and $180 \mathrm{mmHg}$ ) with a rate of three cycles per second $(\mathrm{Hz})$. Mean pressures were calculated for a 24-hour period and compared between groups using one-way ANOVA. Bonferroni corrected, two-tailed $\mathrm{p}$ values were used to establish statistically significant differences using $\alpha=$ 0.05 as the initial criterion.

\section{Results}

Use and rheological properties

Rheological measurements showed that all materials exhibited shear storage moduli $(G$ ') greater than shear loss moduli (G”), at all frequencies and $50 \mathrm{~Pa}$ oscillatory stress, indicating that the samples are more elastic than viscous (Figure 3). At $1 \mathrm{~Hz}$, Dermabond exhibited the highest $G^{\prime}$ value $\left(1.51 \times 10^{7} \mathrm{~Pa}\right)$ followed by BioGlue $\left(2.04 \times 10^{6} \mathrm{~Pa}\right)$, Omnex $\left(2.47 \times 10^{5} \mathrm{~Pa}\right)$, PEG-LysNH ${ }_{2}$ $\left(1.16 \times 10^{4} \mathrm{~Pa}\right)$ and Evicel $\left(3.7 \times 10^{3} \mathrm{~Pa}\right)$. Samples exhibiting high G' (e.g. Dermabond, BioGlue and Omnex) (Figure 3A) were stiffer than the samples with lower G' (e.g. PEG-LysNH ${ }_{2}$ and Evicel) (Figure 3B), likely due to an increase in the cross-link density of their formed network. The loss tangent values $\left(\tan \delta=G^{\prime \prime} / G^{\prime}\right)$ were lower than 1 for all materials at the investigated frequency of $1 \mathrm{~Hz}(\tan \delta=0.2,0.05,0.7,0.04$, and 0.3 for Dermabond, BioGlue, Omnex, PEG-LysNH $\mathrm{H}_{2}$, and Evicel, respectively, at $1 \mathrm{~Hz}$ ) with smaller $\tan \delta$ values indicating a more solid-like material.

Table 1 Mechanism of action of the products used in the study

\begin{tabular}{|c|c|c|c|}
\hline Agent & $\begin{array}{l}\text { Brand } \\
\text { Name }\end{array}$ & Category & Mechanism of action \\
\hline $\begin{array}{l}\text { Glutaraldehyde cross-linked } \\
\text { albumin }\end{array}$ & BioGlue & Sealant & $\begin{array}{l}\text { Glutaraldehyde cross-links bovine albumin to cell proteins at wound site to form a tough } \\
\text { scaffold [2]. }\end{array}$ \\
\hline Fibrin sealant (human) & Evicel & $\begin{array}{l}\text { Sealant, } \\
\text { hemostatic } \\
\text { agent }\end{array}$ & $\begin{array}{l}\text { Thrombin and fibrinogen mixed at site of application; thrombin cleaves fibrinogen to } \\
\text { clot-forming fibrin [2]. }\end{array}$ \\
\hline Butyl lactoyl cyanoacrylate & Omnex & Adhesive & $\begin{array}{l}\text { Liquid monomers that rapidly form polymers in the presence of water and thereby quickly } \\
\text { glue surfaces together [2]. }\end{array}$ \\
\hline 2-octyl cyanoacrylate & Dermabond & Adhesive & $\begin{array}{l}\text { Liquid monomers that rapidly form polymers in the presence of water and thereby quickly } \\
\text { glue surfaces together [2]. }\end{array}$ \\
\hline $\begin{array}{l}\text { Lysine-based dendritic } \\
\left.\text { hydrogel (PEG-Lys } \mathrm{NH}_{2}\right)\end{array}$ & $\begin{array}{l}\text { Not } \\
\text { available }\end{array}$ & Sealant & $\begin{array}{l}\text { The cross-linked hydrogel forms an adhesive physical barrier on the wound's surface } \\
\text { [5] - hemostasis is not dependent on the clotting cascade. }\end{array}$ \\
\hline
\end{tabular}




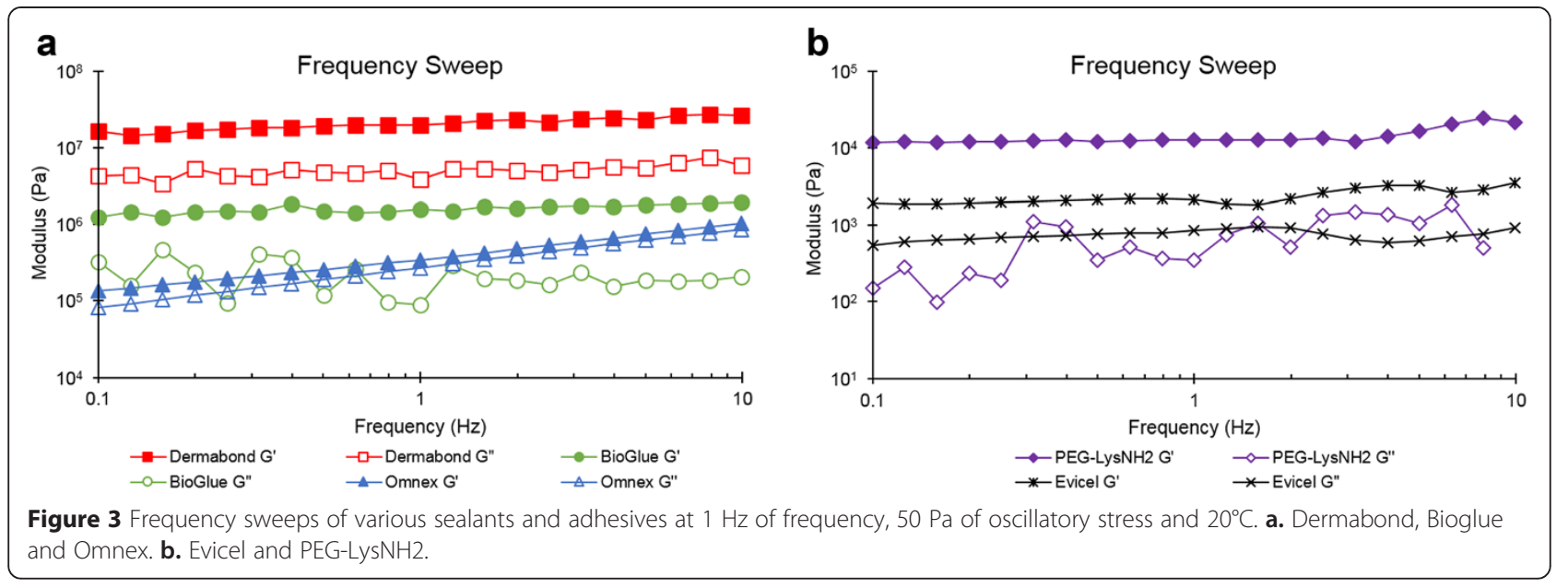

\section{Resistance to failure}

When applied to $2.5 \mathrm{~mm}$ incisions under dry conditions, all products withstood pressures greater than $250 \mathrm{mmHg}$ without signs of failure or leakage. $\mathrm{P}_{30}$ in sealed groups ranged between $206.36-220.17 \mathrm{mmHg}$ and no statistically significant differences were observed between the groups $(\mathrm{p}=0.94) \quad$ (Figure 4$)$. The control and suture groups had lower mean $\mathrm{P}_{30}$, when compared to sealed groups, as the pressure increase was hindered by active fluid loss ( $p<0.001$ for control and $p=0.013$ for suture, Bonferroni-corrected $\alpha=0.025$ for 2 tests). The average relative standard error for the $\mathrm{P}_{30}$ measurements was $4.97 \pm 1.84 \%$.

\section{Endurance}

All products held the shear stresses of fluctuating pressures for a 24-hour period. Mean pressures ranged between $135.20-160.09 \mathrm{mmHg}$, and there were no differences between the products or between the products and the control group composed of intact tissues $(\mathrm{p}=$ 0.96) (Figure 5). The novel PEG-LysNH ${ }_{2}$ was able to seal the incisions in both ex-vivo vascular and dermal tissues.

\section{Discussion}

Sealants, adhesives and hemostatic agents are useful adjuncts to surgical care, as they can reduce operative times, improve the quality of surgical tissue management, and decrease bleeding [2]. Applications for these agents include wound closure in skin and mucosal surfaces, sealing of intestinal and vascular anastomoses, prevention of cerebrospinal fluid leakage, fixation of surgical devices and grafts and hemorrhage control across all surgical specialties $[2,6-8]$. Products with new properties, such as the ability to deliver antimicrobial medications or

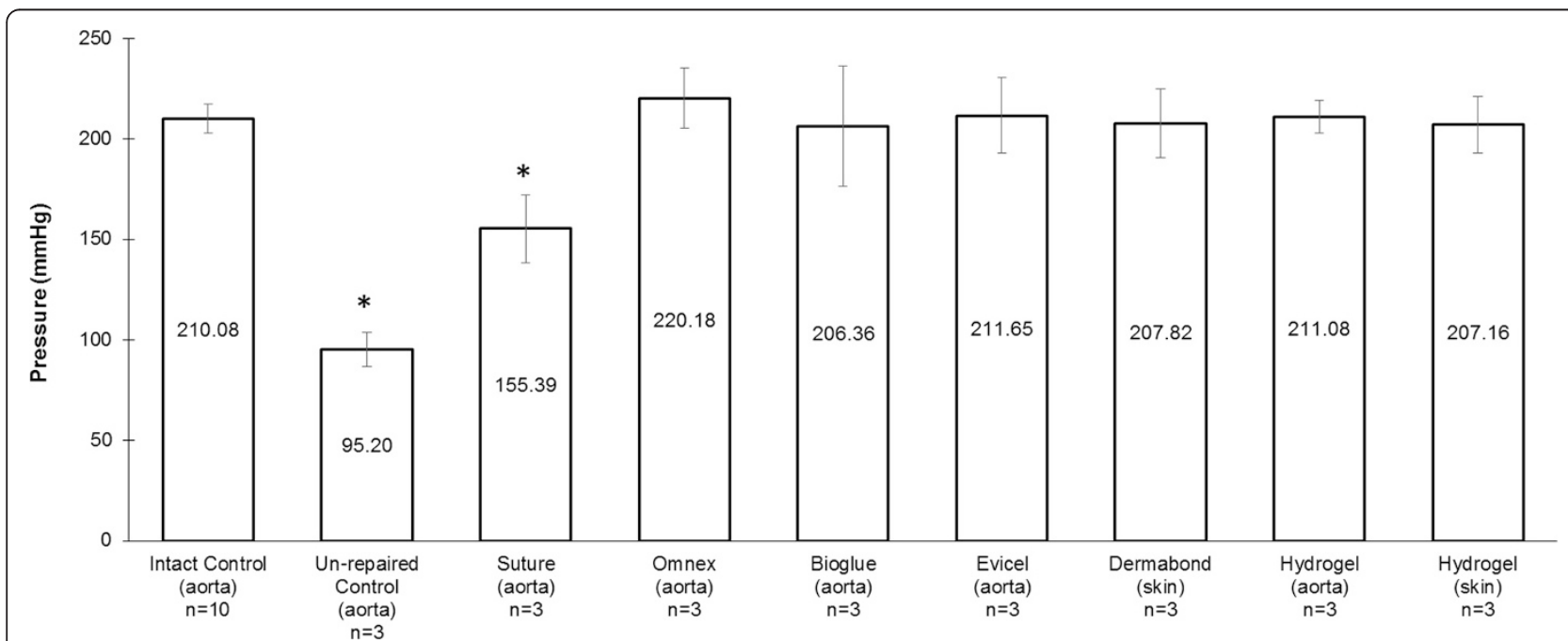

Figure 4 Resistance to failure. Pressure was gradually increased within the system and measured at 30 seconds $\left(\mathrm{P}_{30}\right)$. Mean pressure values are reported for each group. Asterisks $\left(^{*}\right)$ denote statistically significant differences after ANOVA with Bonferroni correction. 


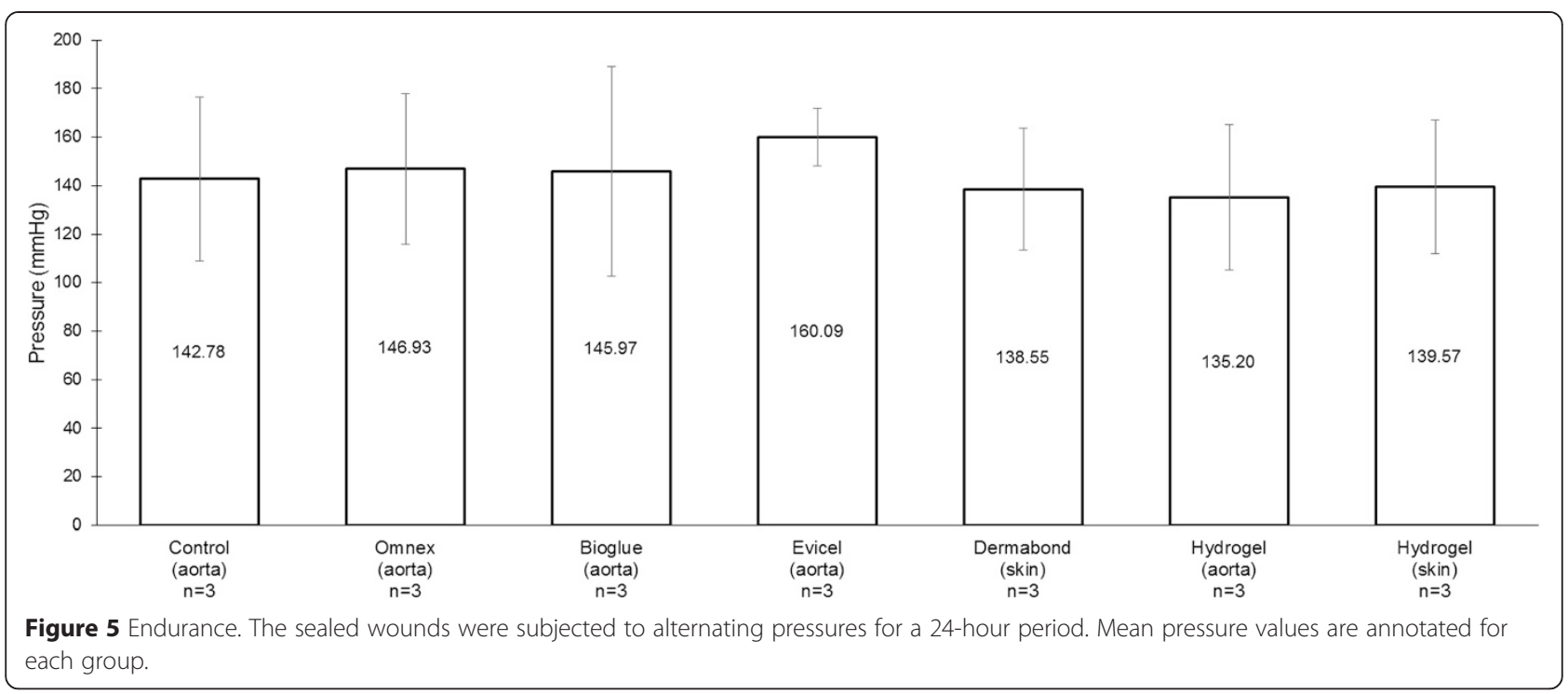

to reversibly seal the wound allowing gradual re-exposure of the injury and sparing the need for debridement [5], could further reduce morbidity and improve patient outcomes.

Even though animal experimentation plays a fundamental role in the development of sealants, adhesives and hemostatic agents, the efficacy of new materials and formulations should be evaluated before proceeding to testing in animal hemorrhage models. Researchers should replace, reduce and refine $[9,10]$ the use of animal models whenever possible; ex-vivo pressure testing offers an alternative to animal models and a means to optimize development. In order to reduce the number of animal experiments and in accordance with the guiding principles for the ethical use of animals in testing $[9,10]$ we conducted this study in a simulated model of hemorrhage using ex-vivo tissues. A similar approach has been used to evaluate the strength of sealants used in the repair of cerebrospinal fluid leak [11].

The adhesives and sealants used in this study, exhibiting different dynamic mechanical strength ranging from stiff to rigid, were subsequently tested in an ex-vivo model of venous and arterial hemorrhage to determine their wound-closure performance. Although the materials exhibited different dynamic mechanical properties, they were able to seal ex-vivo injuries and withstand physiological pressures: furthermore, their efficacy was superior to that of simple suturing techniques. In particular, the PEG-Lys $\mathrm{NH}_{2}$, a novel sealant in the initial phases of development, was included in our tests: its performance did not differ from those of previously approved sealants and adhesives, and it was also superior to simple sutures, thus confirming its sealant efficacy for small ex-vivo arterial injuries under pressures of up to $250 \mathrm{mmHg}$ and for periods up to 24 hours.
An ideal surgical tissue adhesive or sealant should exhibit rapid adhesion to injured tissues and maintain strong and close apposition of wound edges for an amount of time sufficient to allow wound healing $[12,13]$. An ideal hemostatic agent should meet the requirements for tissue adhesives and also exhibit the following additional properties: 1) stop hemorrhage from actively bleeding vessels; 2) maintain physiological pressures for several hours; and 3) be easily applied to the tissue with a user-friendly procedure [14]. Thus far, the PEG-LysNH ${ }_{2}$ has demonstrated to be adherent to ex-vivo tissues, resistant and easily applied, but it has yet to prove its efficacy in controlling active hemorrhage in in-vivo models of hemorrhage. In subsequent development stages, and in order to evaluate the efficacy of the PEG-LysNH $\mathrm{H}_{2}$ as a hemostatic agent, we will assess its efficacy in a well-established small animal model of uncontrolled hemorrhage [15], and, if successful, proceed to a large animal model: the logical steps in the design or evaluation of new hemostatic agent formulations.

Several limitations are evident when testing the efficacy of the PEG-LysNH $\mathrm{H}_{2}$ using the proposed ex-vivo model. As it is presented in this study, the model is unable to assess the efficacy of hemostatic agents, as their basic mechanism of action relies on the activity of the clotting cascade. Additionally, physiologic outcomes such as survival, mean arterial pressure resuscitation fluid usage are often used to evaluate hemostatic agent efficacy [16]. To date, no ex-vivo model has been able to simulate the actual pathophysiologic response to injury and stress, making animal models irreplaceable in subsequent stages of product development. Therefore, with this study's results it is only valid to conclude that the PEG-Lys $\mathrm{NH}_{2}$ meets the basic requirement of a tissue adhesive or sealant: it physically adheres to and seals injured 
tissues, thereby preventing fluid loss in a physiologic pressure range.

\section{Conclusion}

In conclusion, all the products evaluated in this study including the novel PEG-LysNH $\mathrm{H}_{2}$ - were able to seal small incisions in ex-vivo skin and vascular tissues with better outcomes than simple suture repairs. These encouraging preliminary results on the efficacy of the PEG-LysNH ${ }_{2}$ show that it meets the basic requirements of tissue adhesives and sealants. In order to justify its use as a hemostatic agent in emergent care scenarios, further research regarding the performance of this novel sealant in in-vivo models of uncontrolled hemorrhage is necessary.

\section{Competing interests}

The authors declare that they have no competing interest. This work was supported in part by the NIBIB (R21 EB013721).

\section{Authors' contributions}

JCV-C: Literature search, study design, data collection, data analysis, manuscript writing. CG: Study design, data collection, data analysis, manuscript writing. LA-B: Study design, data collection, critical revision of the article. MWG: Study design, critical revision of the article. EKR: Study design, critical revision of the article. AN: Study design, critical revision of the article. All authors read and approved the final manuscript.

\section{Acknowledgments}

This work was supported in part by the National Institute of Biomedical Imaging and Bioengineering - NIBIB (R21 EB013721), the Department of Orthopaedic Surgery at Beth Israel Deaconess Medical Center - Harvard Medical School, and Boston University. The authors would like to acknowledge Steven Fletcher from Ethicon Biosurgery and Peter Gross from CryoLife for supplying some of the products used in this study.

\section{Author details}

${ }^{1}$ Center for Advanced Orthopaedic Studies, Department of Orthopaedic Surgery, Beth Israel Deaconess Medical Center, Harvard Medical School, Boston, MA, USA. '2Departments of Biomedical Engineering and Chemistry, Boston University, Boston, MA, USA. ${ }^{3}$ Carl J Shapiro Department of Orthopaedic Surgery, Beth Israel Deaconess Medical Center, Harvard Medical School, Boston, MA, USA.

Received: 18 November 2014 Accepted: 29 April 2015

Published online: 13 May 2015

\section{References}

1. Gruen RL, Brohi K, Schreiber M, Balogh ZJ, Pitt V, Narayan M, et al. Haemorrhage control in severely injured patients. Lancet. 2012;380:1099-108.

2. Spotnitz WD, Burks S. Hemostats, sealants, and adhesives: components of the surgical toolbox. Transfusion. 2008:48:1502-16.

3. Kheirabadi B. Evaluation of topical hemostatic agents for combat wound treatment. US Army Med Dep J. 2011:25-37.

4. Achneck HE, Sileshi B, Jamiolkowski RM, Albala DM, Shapiro ML, Lawson JH. A comprehensive review of topical hemostatic agents: efficacy and recommendations for use. Ann Surg. 2010;251:217-28.

5. Ghobril C, Charoen K, Rodriguez EK, Nazarian A, Grinstaff MW. A dendritic thioester hydrogel based on thiol-thioester exchange as a dissolvable sealant system for wound closure. Angew Chem Int Ed Engl. 2013;52:14070-4.

6. Spotnitz WD. Hemostats, sealants, and adhesives: a practical guide for the surgeon. Am Surg. 2012;78:1305-21.

7. Spotnitz WD, Burks S. Hemostats, sealants, and adhesives III: a new update as well as cost and regulatory considerations for components of the surgical toolbox. Transfusion. 2012;52:2243-55.
8. Spotnitz WD, Burks S. State-of-the-art review: Hemostats, sealants, and adhesives II: Update as well as how and when to use the components of the surgical toolbox. Clin Appl Thromb Hemost. 2010;16:497-514.

9. van Zutphen LF, van der Valk JB. Developments on the implementation of the Three Rs in research and education. Toxicol In Vitro. 2001;15:591-5.

10. Russell WMS, Burch RL. The Principles of Humane Experimental Technique. London: Methuen \& Co; 1959.

11. de Almeida JR, Ghotme K, Leong I, Drake J, James AL, Witterick IJ. A new porcine skull base model: fibrin glue improves strength of cerebrospinal fluid leak repairs. Otolaryngol Head Neck Surg. 2009;141:184-9.

12. Mizrahi B, Weldon C, Kohane D. Tissue Adhesives as Active Implants. In: Zilberman M, editor.Active Implants and Scaffolds for Tissue Regeneration. Springer-Verlag; 2011. p. 39-56.

13. Mobley SR, Hilinski J, Toriumi DM. Surgical tissue adhesives. Facial Plast Surg Clin North Am. 2002;10:147-54.

14. Alam HB, Burris D, DaCorta JA, Rhee P. Hemorrhage control in the battlefield: role of new hemostatic agents. Mil Med. 2005;170:63-9.

15. Matsuoka T, Hildreth J, Wisner DH. Liver injury as a model of uncontrolled hemorrhagic shock: resuscitation with different hypertonic regimens. J Trauma. 1995;39:674-80.

16. Kheirabadi BS, Sieber J, Holcomb JB. Assessment of the thrombogenic effect of fibrin sealant dressing in a vascular surgery model in rabbits. J Invest Surg. 2006;19:387-96.

\section{Submit your next manuscript to BioMed Central and take full advantage of:}

- Convenient online submission

- Thorough peer review

- No space constraints or color figure charges

- Immediate publication on acceptance

- Inclusion in PubMed, CAS, Scopus and Google Scholar

- Research which is freely available for redistribution 